\title{
SUSTENTABILIDADE E GOVERNANÇA PARTICIPATIVA
}

\author{
Maria Lenir Rodrigues Pinheiro* \\ Ricardo Stanziola Vieira **
}

\section{Resumo}

O presente artigo visa demonstrar a relevância da governança participativa a partir do bojo da interação entre o Estado e a sociedade e o relacionamento entre governabilidade e sustentabilidade para enfrentar contextualizações complexas, instáveis e voláteis. Analisa a exclusão social e a pobreza e seus desdobramentos na conjuntura moderna a partir do planejamento estratégico estatal onde gerações futuras serão alcançadas. Utilizou-se o Método Indutivo, tanto na Fase de Investigação quanto na apresentação do relato dos seus resultados e, conjuntamente, foram adotadas as Técnicas do Referente, da Categoria, do Conceito Operacional e da Pesquisa Bibliográfica.

Palavras-chave: Governança Participava; Sustentabilidade; Economia; Estado; Sociedade.

\section{SUSTAINABILITY AND PARTICIPATIVE GOVERNANCE}

\begin{abstract}
The present article aims to demonstrate the relevance of participatory governance based on the interaction between the State and society and the relationship between governance and sustainability to face complex contextualizations, unstable and volatile. Analyzes the social exclusion and poverty and its unfolding in the modern conjuncture from the state strategic planning where future generations will be reached. The Inductive Method was used both in the Investigation Phase and in the presentation of the report of its results and, together, the Techniques of the Referent, the Category, the Operational Concept and the Bibliographic Rese $^{\dagger}$ arch were adopted.
\end{abstract}

Keywords: Participative Governance; Sustainability; Economy; State; Society.

\footnotetext{
* Mestra em Ciência Jurídica pela Universidade do Vale do Itajaí - UNIVALI, Doutoranda em Ciência Jurídica pela UNIVALI. Docente do Centro Universitário do Norte - UNINORTE e Centro Universitário de Ensino Suiperir do Amazonas - CIESA. Manaus/AM/BR, e-mail: lenirpinheiro@gmail.com.

** Mestre em Direito pela Universidade Federal de Santa Catarina, Doutorado em Ciências Humanas pela Universidade Federal de Santa Catarina, Pós-Doutorado no Centro de Pesquisa Interdisciplinar em Direito Ambiental, Urbanismo e gestão do território pela Universidade de Limonges - França. Docente nos Cursos de Mestrado e Doutorado do Programa de Pós-Graduação Stricto Sensu em Ciência Jurídica e no Curso de Mestrado em Gestão de Políticas Públicas da UNIVALI. Itajaí/SC/BR, e-mail: ricardostanziola@univali.br.
} 


\section{INTRODUÇÃO}

O presente artigo tem o objetivo de demonstrar a relevância da governança participativa a partir do bojo da relação e interação entre o Estado e a sociedade, ultrapassando o relacionamento de governabilidade e sustentabilidade no sentido destas virem a enfrentar contextualizações envolventes e cada vez mais complexas, instáveis e voláteis.

Observa-se, nas últimas décadas, a intensificação das interações econômicas, sociais, políticas e culturais, tendo em vista o fenômeno da globalização, onde há um conjunto de trocas desiguais onde o local e o global são socialmente produzidos, não possuindo a mesma unidade de causas e consequências sociais, nos colocando diante da exclusão social e a pobreza, suas diversidades, similitudes e seus desdobramentos na conjuntura moderna.

Atualmente, a pobreza passa a configurar uma das preocupações mundiais e, em conjunto com a exclusão social, passam a ser alvos da busca incessante do Estado na efetivação dos direitos ao desenvolvimento, a partir dos desdobramentos do papel político, econômico e social do Estado e da governança frente à globalização e o capitalismo que geram riscos à sobrevivência desta e das gerações futuras.

Verificar-se-á que a assistência ao desenvolvimento dos países pobres emerge, urge, da realização de ações coordenadas dos países ricos, bem como dos próprios países pobres, refletindo na efetivação e concretização dos Direitos ao desenvolvimento e do desenvolvimento por meio de uma governança sustentável participativa, que no caso aqui tratado, versará sobre a relação entre Estado e sociedade.

Com a implantação e implementação de uma governança participativa, um planejamento estratégico, estar-se-á habilitado a adentrar o âmbito socioeconômico e modificar alguns fatores da realidade em que o cidadão vive e assim, gerações futuras serão alcançadas, o combate e erradicação da pobreza será mais efetivo, tornando o futuro mais próspero.

Na elaboração do artigo foi utilizado o Método Indutivo, tanto na Fase de Investigação quanto na apresentação do relato dos seus resultados e, conjuntamente, foram adotadas as Técnicas do Referente, da Categoria, do Conceito Operacional e da Pesquisa Bibliográfica (PASOLD, 2011). 


\section{SOCIEDADE, GESTÃO PÚBLICA E DESENVOLVIMENTO SUSTENTÁVEL}

A democracia participativa é uma proposta a ser introduzida no seio da sociedade. Há necessidade que o gestor público recicle os seu modus operandi e inicie um processo de negociação participativa com os diversos indivíduos da sociedade, saindo assim, da redoma técnica e exercitando a política pública.

Esse processo de discussão e negociação com a sociedade, com os diversos atores, resultaria em um planejamento estratégico, com a adoção de ações governamentais, de médio e longo prazo, de forma a legitimar e viabilizar uma governança eficaz.

\subsection{A concepção de democracia participativa}

A concepção da democracia participativa é criticada por Costa e Rodrigues (2016, p.3) que asseveram que não é possível erigir um Estado minimamente eficaz (enquanto ator) no prisma da configuração, delineamento, gestão e implementação de políticas públicas, bem como enquanto entidade político-planificadora, descartando-se a técnico-burocracia.

Segundo os autores,

$\mathrm{Na}$ verdade, se é fato que o paradigma weberiano teria sido superado, o que se deveria buscar, no contexto de uma abordagem neoweberiana, seria a formação de uma neoburocracia, muito mais profissional, meritocrática e estratégica do que a burocracia weberiana típica. Esta técnico-burocracia de tipo novo estaria de acordo com a busca por um Estado mais flexível, eficiente e estratégico (e até contingencial). (COSTA, RODRIGUES, 2016, p. 3)

Ainda seguindo a crítica à configuração do Estado, Costa e Rodrigues (2016, p. 6) apontam que

[...] o modelo de Estado vertical não pode ser tomado como o vilão de todas as estórias, pois há que recordar que partindo da experiência prussiana, passando pelo projeto varguista e chegando, aos dias de hoje, às pujantes economias do Sudeste Asiático, a concepção vertical-estatista até que não se saiu muito mal. Na verdade, se o estado keynesiano entrou em crise na década de 70 do século XX, cedendo espaço ao projeto neoliberal, o Estado técnico-burocrático-estratégico neoconfuciano parece se encontrar de plena saúde.

Rev. de Direito, Economia e Desenvolvimento Sustentável| e-ISSN: 2526-0057| Maranhão | v. 3 | n. 2 | p. 119 - 135 | Jul/Dez. 2017. 
Observa-se que a questão pousa na necessidade de se ter um Estado modernizador, interagindo com a sociedade, descentralizando, com maiores níveis de eficácia e eficiência, nas tomadas de decisão, de forma a implementar as políticas públicas de forma estratégica e harmoniosa.

Destarte, não se pode pensar que a interação entre Estado e sociedade autoriza a ausência e/ou diminuição do planejamento estratégico, comprometendo a intervenção e regulação estatal, ou seja, a vertente participativa não pode comprometer e anular a capacidade de planejamento e a estrutura técnico-burocrática do Estado ao desempenhar as suas funções.

Nesta senda, Ferrarezi (1997, p. 2) pontua que os defensores da sociedade participativa buscam a intensificação da participação e afirmação do terceiro setor, composto pelas organizações sociais públicas não estatais, tomando como básico o que deveria estar na ponta do sistema social e não visam a reconstrução e modernização do Estado.

Ao refletir sobre a vertente participativa, Ferrarezi (1997, p. 3) nos conduz à finalidade real do seguimento da sociedade que defende uma maior participação da população, consistindo no questionamento do Estado enquanto interventor, regulador e político-administrativo, inviabilizando a gestão política e impedindo a promoção de capital, como a educação e saúde, o investimento em ciência e tecnologia que se mostram como variáveis estratégicas no âmbito da economia mundial.

Conclui a autora,

[...] A resistência de estratos burocráticos deve ser considerada em um processo de mudança institucional, sob o risco de fracassarem as tentativas de implementação de novos padrões de atuação no campo social. Reafirmamos o entendimento de que a participação social fortalece a capacidade das pessoas se envolverem com e se responsabilizarem pelo desenvolvimento social, resolvendo problemas comuns. Igualmente, possibilita a supervisão de forma mais contínua dos resultados dos serviços, adaptando-os às suas necessidades e valores, podendo assegurar a continuidade dos programas por ocasião das mudanças de administração. (FERRAREZI, 1997, p. 4)

\subsection{O desenvolvimento sustentável}

No início dos anos setenta, o conceito de desenvolvimento sustentável surgiu com o nome de Eco Desenvolvimento, com bons presságios, pela publicação do relatório do Clube de Roma, que pregava o crescimento zero como forma de evitar a catástrofe ambiental, em um contexto de controvérsias sobre as relações entre crescimento econômico e meio ambiente (MAY; LUSTOSA; VINHA, 2010). 
Essa questão foi discutida, incialmente, conforme preleciona Bellen (2006, p. 45), pela World Conservation Union no documento intitulado World's Conservation Strategy, no qual consta que para haver desenvolvimento sustentável, faz-se necessário considerar aspectos referentes às dimensões social e ecológica, assim como os aspectos econômicos dos recursos vivos e não vivos e as vantagens de curto e longo prazo de ações alternativas.

Postriormente, o foco que estava fixo na integridade ambiental, desloca sua ênfase, a partir do Relatório Brundtland, especialmente para o elemento humano, cobrando um equilíbrio entre as dimensões econômica, ambiental e social (BELLEN, 2006).

$\mathrm{Na}$ segunda metade da década de oitenta, surgiu o mais conhecido e disseminado conceito sobre desenvolvimento sustentável, após a criação da Comissão Mundial para o Meio Ambiente e o Desenvolvimento (CMMAD), ou World Commission on Environment and Development (WCDE), vinculada à Organização das Nações Unidas (ONU), que resultou no Relatório Brundtland.:

[...] desenvolvimento sustentável é um processo de transformação no qual a exploração dos recursos, a direção dos investimentos, a orientação do desenvolvimento tecnológico e a mudança institucional se harmonizam e reforça o potencial presente e futuro, a fim de atender às necessidades e aspirações futuras [...] é aquele que atende às necessidades do presente sem comprometer a possibilidade de as gerações futuras atenderem as suas próprias necessidades (NOSSO FUTURO COMUM, 1988, p. 46).

A relevância e reconhecimento sobre a conceituação adotada pelo Relatório Brundtland se dá pelo fato de envolver a necessidade e a limitação. A necessidade, em particular, às necessidades essenciais dos países subdesenvolvidos do planeta, para os quais a atenção deve ser priorizada e os limites sobre o uso da tecnologia e a organização social para manter a capacidade do meio ambiente no atendimento das necessidades das gerações presentes e futuras.

Fica ainda evidente, dentro do conceito de desenvolvimento sustentável que não há um estado estático, pois o processo de crescimento pode continuar a ocorrer sem a existência da lógica autodestrutiva predominante.

A despeito disso, faz-se necessário estabelecer, para a conceituação, critérios e consenso com a finalidade de definir o que é "não comprometer a capacidade de gerações 
futuras", visto que aquilo que é primordial para as gerações atuais pode não ser de tamanha relevância para as futuras.

De acordo com a CMMAD (1998), os principais objetivos de políticas derivadas desse conceito de desenvolvimento sustentável são: retomar o crescimento como condição necessária para erradicar a pobreza; mudar a qualidade do crescimento para torná-lo mais justo, equitativo e menos intensivo em matérias-primas e energia; atender às necessidades humanas essenciais de emprego, alimentação, energia, água e saneamento; manter um nível populacional sustentável; conservar e melhorar a base de recursos; reorientar a tecnologia e administrar os riscos; e incluir o meio ambiente e a economia no processo decisório.

Sobre a preocupação com a problemática do desenvolvimento sustentável, Sachs acrescenta as dimensões cultural, geográfica e política para explicar a sustentabilidade e o consequente desenvolvimento sustentável, afirmando que ao atuarem no sistema - social, econômica, ambiental e institucional - irão conduzir ao equilíbrio.

Segundo o estudioso, na dimensão econômica, os olhares devem estar voltados para o desenvolvimento econômico intersetorial equilibrado e atentar para a segurança alimentar, busca de capacitação contínua dos instrumentos de produção, diversificação dos produtos e mercados e garantia na geração de renda.

Explana ainda, o doutrinador, que na dimensão social, seria preciso manter uma homogeneidade social, distribuição justa de renda, geração de empregos, qualidade de vida e igualdade no acesso aos recursos e serviços. Já na ambiental, ele ressalta o respeito pela capacidade de autodepuração dos ecossistemas naturais, preservação do potencial do capital natural na sua produção de recursos renováveis, bem como no limite e uso correto dos recursos não renováveis. E, por fim, na dimensão institucional, seria preciso assegurar o compromisso e a capacidade do Estado em implementar políticas e projetos voltados para o desenvolvimento da sociedade, bem como manter um nível razoável de coesão social (SACHS, 2009).

Destaca-se que, de acordo com o exposto, pode parecer que a temática do desenvolvimento sustentável apresente um consenso em sua conceituação; entretanto, ele é marcado por vários obstáculos em sua operacionalização, no que vem a ser realmente o desenvolvimento sustentável.

Rev. de Direito, Economia e Desenvolvimento Sustentável| e-ISSN: 2526-0057| Maranhão | v. 3 | n. 2 | p. 119 - 135 | Jul/Dez. 


\section{DESENVOLVIMENTO SUSTENTÁ VEL E A ECONOMIA NO MEIO AMBIENTE}

A preocupação com a implementação e implantação de políticas públicas e projetos voltados para a sustentabilidade, desenvolvimento da sociedade, como supracitado, com o fito de manter e elevar um nível de coesão social levou à inclusão das atividades econômicas no meio ambiente.

\subsection{A inclusão da atividade econômica no meio ambiente}

Tal inclusão compreende a existência de relações e de interações recíprocas entre o homem e o seu meio exterior. A percepção das relações entre a economia, os recursos naturais e o meio ambiente, que despertou de forma temporal, como um problema, levou os agentes e atores a vislumbrarem um risco de esgotamento dos recursos naturais, com o agravamento dos danos causados ao meio ambiente. Para que a noção de desenvolvimento sustentável não se torne vago, há a necessidade de aprofundar--lhe as condições e definir os critérios de gestão correspondentes. A economia, desta forma, defronta--se com alguns problemas relevantes, como: a multidimensionalidade; a irreversibilidade; a presença de problemas de equidade, tanto intrageracionais como intergeracionais; e a incerteza. (FAUCHEUX; NOËL, 1995).

Concernente à multidimensionalidade, os problemas deixaram de ser isoláveis uns dos outros, comportando várias dimensões, ou seja, as interações entre as esferas econômica, natural e sociocultural nada mais são do que a relação entre economia, os recursos e o ambiente.

Respeitante à irreversibilidade, esta constitui um conjunto de fatores caracterizados por processos de extinção de espécies, causados por alterações e permanentes agressões dohomem à natureza, que modificam as condições de vida. Desta feita, toda a perda de patrimônio genético pode ser considerada como definitiva, considerando-se, portanto, essencialmente irreversível.

No tocante à presença de problemas de equidade, tanto intrageracionais como intergeracionais, estes são explicados pelo tempo. Para que o mesmo bem-estar usufruído na atualidade esteja disponível para as gerações futuras, é necessário, sopesar o equilíbrio e a salvaguarda na exploração e uso dos recursos disponíveis no presente. Isso torna o processo de equidade delicado, pois as regras estabelecidas hoje para assegurar a partilha dos recursos para as gerações vindouras podem não estar de acordo com suas necessidades e costumes.

Rev. de Direito, Economia e Desenvolvimento Sustentável| e-ISSN: 2526-0057| Maranhão | v. 3 | n. 2 | p. 119 - 135 | Jul/Dez. 
Finalmente, não menos importante, temos a incerteza, presente em todo o domínio dos recursos naturais e do meio ambiente que se coloca frente às reservas de recursos naturais esgotáveis, à evolução e ao progresso tecnológico, às consequências globais da poluição; nesse aspecto, a combinação da irreversibilidade com a incerteza leva ao princípio da precaução como extensão ao termo desenvolvimento sustentável.

\subsection{Desenvolvimento sustentável e a economia}

Para May (2001), a corrente de pensamento da economia ambiental corrobora a ideia neoclássica que propaga o equilíbrio de mercado e a soberania do consumidor em decidir pelas suas preferências por meio da capacidade de pagar quando ocorre o ajuste entre preços via oferta e demanda. Esse mesmo processo pode ser estendido para os ajustes nas externalidades ambientais. Essa corrente defende que a questão da sustentabilidade pode ser incorporada sob a mesma ótica.

Nesta senda, aduz que os estudiosos do assunto defendem, ainda, a crença de que o progresso tecnológico poderá substituir todo e qualquer recurso natural que venha a impor limites ao crescimento econômico tendo em vista que o mecanismo de preço, pelo qual se alcança a alocação eficiente dos recursos, assinala adequadamente a escassez emergente e os ajustes necessários para criação/substituição de recursos utilizados na fabricação dos bens e serviços procurados, indicando a inovação na busca por novos materiais e fonte de energias demandadas (MAY, 2001).

Conforme Romeiro (2010, p. 1), tudo acontece como se o sistema econômico fosse capaz de se mover a partir de uma base de recursos disponíveis para outra à medida que cada uma se esgota. O progresso técnico-científico é o elemento-chave para tal acontecimento, não impondo, sobremaneira, limites para o crescimento: tal concepção ficou conhecida como sustentabilidade fraca.

Essa ideia parte da premissa de que o investimento compensa as gerações futuras em razão das perdas de ativos, causadas pelo consumo e produção correntes, podendo, de acordo com o caso, até haver exploração ineficiente dos recursos naturais; mas considera-se que políticas adequadas voltadas para os mecanismos de mercado resolvam esses problemas com facilidade.

Na contrapartida de interpretação do desenvolvimento sustentável surge a economia

Rev. de Direito, Economia e Desenvolvimento Sustentável| e-ISSN: 2526-0057| Maranhão | v. 3 | n. 2 | p. 119 - 135 | Jul/Dez. 
ecológica, que olha o sistema econômico como um subsistema de um todo maior que o envolve, impondo-lhe restrições ao crescimento. O progresso científico e tecnológico é visto como fundamental para elevar a eficiência na utilização dos recursos naturais (renováveis ou não renováveis) limitados. É nesse sentido que essa corrente centra sua análise, ou seja, em como fazer com que a economia funcione, considerando a existência desses limites (ROMEIRO, 2010).

Cechin e Veiga (2010, p. 82). apontam que existem diferenças entre as duas correntes econômicas (a Ecológica e a Ambiental) a partir dos seus pontos de origem. Segundo os autores, a Ambiental enxerga a economia como um todo. Ela considera a natureza, o meio ambiente ou a biosfera (setor florestal, pesqueiro, mineral, agropecuário, áreas protegidas, pontos ecoturísticos, entre outros) como partes ou setores da macroeconomia e a Economia Ecológica faz uma análise contrária, pois para essa corrente a macroeconomia é parte de um todo bem mais amplo, que a envolve e a sustenta.

Desta feita, qualquer expansão da economia implica um custo, pois ocorre a exigência de alguma contrapartida natural. Dito de outra forma, o crescimento econômico não se realiza no vazio, tampouco é gratuito; representa um custo que pode tornar-se superior ao benefício em certas circunstâncias, que gera um crescimento antieconômico. A economia ecológica leva em conta todos os custos (não apenas os monetários) do crescimento da produção material (CECHIN; VEIGA, 2010).

Para os citados autores, a economia ecológica, baseada nos preceitos da sustentabilidade forte, defende que a qualidade de vida que poderá ser desfrutada por futuras gerações da espécie humana depende de sua "pegada" ecológica. Por isso, numa análise temporal, a continuidade do desenvolvimento humano, nessa concepção, só se realizará com uma estabilização da produção material, ou até mesmo pelo seu decréscimo.

Em outras palavras, o imperativo de sustentabilidade forte impõe que o estoque de capital natural seja constante, ou seja, o desenvolvimento sustentável é definido nesse contexto como o desenvolvimento máximo que pode ser atingido sem comprometer ou diminuir os ativos de capital natural.

Percebe-se, porém, que numa perspectiva de sustentabilidade que deve ser simultaneamente econômica, social e ecológica, as duas primeiras são sacrificadas apenas em proveito de preocupações ecológicas veementemente defendidas nessa corrente de pensamento 
(FAUCHEUX; NOËL, 1995).

\section{O DESENVOLVIMENTO ECONÔMICO SUSTENTÁVEL}

Feitosa (2013, p. 106) assevera que "a precarização e a diferenciação nas relações de trabalho representam fatores que, aliados à crise do Estado de Bem-Estar, especialmente na chamada periferia do mundo capitalista, levaram à enorme exclusão e a desigualdades sociais. Mais do que explorados, este processo começou a gerar um exército de excluídos, entes vulneráveis que sequer conseguem pertencer ao mercado de consumidores".

Estamos diante da exclusão social, fenômeno onde a sociedade consumidora ocidental pode ser seccionada entre aqueles que têm cartão de crédito, os que não os têm, mas gostariam de possuir e os que nunca ouviram falar sobre ele. Gera-se assim, o desejo no indivíduo de alcançar o status do outro, buscando satisfação social e pessoal. Feitosa afirma que:

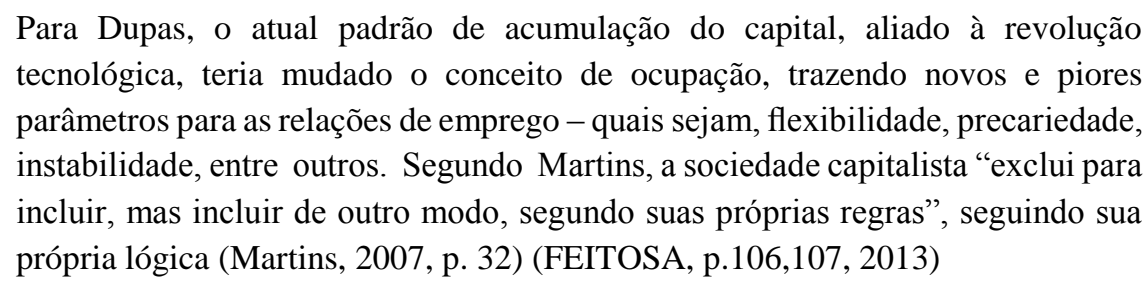

Defrontamo-nos com a mensuração na qual a vida e a sua satisfação passa é medida pelo possuir, ou seja, pelo ter e não pelo ser. Essa exclusão social abre um leque para análises sobre diversas óticas somo econômicas, políticas, sociológicas, antropológicas, psicológicas, assim como questões relacionadas à segurança, justiça e cidadania, abordando o desemprego, trabalho análogo à escravidão, baixa oferta no mercado de trabalho, dificultando o acesso a serviço e bens.

Guarry Rogers conceitua como os velhos excluídos, as pessoas que sempre viveram em situação de exploração e como os novos excluídos os grupos integrados, mas marginalizados do padrão de desenvolvimento considerado ideal em razão de guerras ou crises econômicas. (SACHS, 2005)

Observa-se, cada vez mais, uma crescente preocupação com a integração desses grupos, tanto os excluídos quanto os recentemente incluídos por meio de políticas públicas sociais do Estado Moderno. Assim, segue Feitosa ao expor que

Para aqueles Estados cujos governos abraçam orientação social, importa adotar as necessárias políticas públicas de inclusão, nos mais variados campos; para o

Rev. de Direito, Economia e Desenvolvimento Sustentável| e-ISSN: 2526-0057| Maranhão | v. 3 | n. 2 | p. 119 - 135 | Jul/Dez. 
mercado e para a sociedade civil, os mecanismos da inclusão passam pela instrumentalização de recursos econômicos e humanos, a serem repassados ao Estado sob a forma de contribuição [...] que abrangem a responsabilização dos agentes na urgente tarefa de promoção da igualdade social e da proteção dos vulneráveis. (FEITOSA, p. 109, 2013)

Para Furtado (2002, p. 68), o modelo ideal de desenvolvimento é aquele no qual a "exclusão pode ainda estar vinculada ao tipo de desenvolvimento adotado pelo país, sabendose que não se trata, no caso dos países periféricos, de uma opção. Neste ponto, no Brasil, cabe destacar a dimensão histórica e estrutural da exclusão, gerada pela divisão social de trabalho e pelos processos de exploração capitalistas. É a dupla crise da periferia, a qual se refere Furtado: a da própria civilização industrial, oriunda da racionalidade instrumental exauriente e a crise de especificadas economias periféricas, em razão da dependência”.

Nos países pobres, diferente dos países ricos e desenvolvidos, a exclusão é aferida por meio de instrumentos de políticas públicas, a partir da satisfação das necessidades básicas ou incapacidade para tal (DUPAS, 2005, p.110).

Em seu estudo sobre a 'linha de pobreza', Sen (2010) a afirma que a definição de pobreza será aquela na qual a sociedade considera como pobre os que a renda não atinge exatamente a indicada pela linha de pobreza visto que esta "deve ser definida a partir da variabilidade interpessoal na conexão entre renda e capacidades [...].” (SEN; KLIKSBERG, 2010)

Para Mestriner (2001, p. 79), a pobreza não é uma questão de escassez de bem-estar, mas sim, a incapacidade para conseguir o bem-estar, consequência da ausência de meios, onde o se busca a reconstrução do Estado, a implementação da ideia de que não há direitos sem responsabilidades, a solidariedade, constituindo-se em instrumentos de concretização dos direitos socioeconômicos, impedindo que tais medidas impeçam a ação estatal.

Em sua concepção, Fonseca (2012, p. 81) afirma que o desenvolvimento econômico abrange uma esfera qualitativa e não quantitativa como o crescimento econômico e a importância da juridicidade das políticas públicas assistenciais na busca constante do desenvolvimento, em vista do aumento de pessoas em condições de extrema hipossuficiência socioeconômica. 


\section{A SUSTENTABILIDADE E A GOVERNANÇA PARTICIPATIVA}

Para adentrar na questão da governança participativa, não podemos olvidar a impossibilidade de separação do desenvolvimento de um Estado com a ideia de cidadania em sua plenitude onde a pobreza e a exclusão social necessitam ser combatidas e ascenderem no desenvolvimento social, econômico e político.

\subsection{O papel da cidadania no mundo moderno}

O conceito de cidadania no Mundo Moderno está relacionado aos Direitos Humanos, seguindo o pensamento Kantiano, em que toda pessoa humana já nasce com direitos inatos, e assim, a cidadania assume laços estreitos com os direitos humanos no Mundo Moderno, passando a ter efetivação internacional (KANT, 2005).

Cumpre destacar que Hannah Arendt (1983, p. 13) concebe a cidadania pautada na liberdade e democracia configurando-se como "o direito a ter direitos", visto que a cidadania abarca conjuntos de direitos que se apresentam como direitos de liberdade, quais sejam, os civis, políticos e sociais, distanciando a era moderna do mundo moderno, posto que não há como conceber cidadania sem liberdade.

Nas palavras de Sorto,

“A cidadania só é possível nos regimes que favoreçam a liberdade, tais como os democráticos. Visto que a liberdade é pressuposto para o exercício dos direitos que ela compreende." (SORTO e MAIA 2009, p.61)

A cidadania em sua plenitude somente é possível com a inserção do homem na comunidade política, por palavras e no espaço público, sem lacunas a serem preenchidas pelomo que Arendt chama de "banalidade do mal"; seria o mal praticado por ninguém, o mal que na verdade se exprime por meio de instrumentos lícitos de formas totalitárias, excluindo a mortalidade e elegendo a natalidade como “[...] categoria central de sua compreensão política e visualiza "a permanente e igualitária capacidade de começar algo novo.” (ARENDT, 1983)

O direito ao desenvolvimento está interligado com os agentes sociais, pelo aprimoramento de políticas públicas e diretrizes programadas para a realização desse desenvolvimento que abrange pessoas físicas, jurídicas e coletividades, no qual o Estado e as organizações internacionais figuram como sujeitos passivos. (FEITOSA, 2013)

Destaca-se que os países pobres devem levar a sério o fim da pobreza e efetivar a

Rev. de Direito, Economia e Desenvolvimento Sustentável| e-ISSN: 2526-0057| Maranhão | v. 3 | n. 2 | p. 119 - 135 | Jul/Dez. 
dedicação dos recursos nacionais para o combate à mesma, ao invés de investir em gastos com guerras, corrupção, disputas e políticas internas. A possibilidade de combate à pobreza e a consequente efetivação do direito ao desenvolvimento levam à necessária elaboração de estratégias de combate e redução da pobreza a partir de um pacto global entre ricos e pobres (SACHS, 2005)

Nesse sentido, leciona Sachs (2005, p. 95), que as Metas de Desenvolvimento do Milênio devem desdobrar-se em cinco partes: diagnóstico diferencial, plano de investimentos, plano financeiro, plano dos doadores e plano da gestão pública, onde os países pobres também emergem como possuidores de necessidades críticas que devem ser tratadas a nível global, não mais regional, por meio de reformas de onde se extrairia o melhor das relações internas e internacionais, bem como tirar melhor proveito do sistema das nações unidas, através de uma ação integrada na qual o mundo pobre receberia do mundo rico e desenvolvido.

\subsection{A governança participativa e seus efeitos}

Assim, em prol de promover uma governança participativa, toda a responsabilidade pelo planejamento estratégico do desenvolvimento nacional deve ficar a encargo do Estado, de modo a situar o país ante as mudanças no âmbito da economia mundial, acentuando o nível de complexidade no qual se insere a economia nacional, de forma a definir novas metodologias de ação, ampliando e atualizando a intervenção estatal.

Destarte, percebe-se que mesmo diante de esforços internacionais, alguns países não se comprometem como signatários fieis e de boa-fé no combate à pobreza. Por essa razão, enquanto os países ricos não são tomados por um entusiasmo genuíno para extirpar a pobreza, deve-se buscar soluções dentro do país, somando esforços da comunidade, eivada do espírito de cidadania e do Estado, como cumpridor de seus deveres, suas obrigações.

Em razão das profundas transformações, principalmente econômicas e produtivas, nas últimas décadas do século passado, o contexto internacional está se tornando mais relevante em virtude de sua complexidade e incerteza. Desta feita, o Estado passa a ser o elemento fundamental para o enfrentamento de várias situações econômicas, financeiras, como planejador estratégico, a fim de que se defina um novo modelo de regulação e novos paradigmas.

De acordo com Porto (1998, p. 22-33), o planejamento estratégico deve ser um 
instrumento que promova a adaptação da economia diante das constantes transformações por meio de metodologias direcionadas a dar suporte à gestão governamental, resultando em um conhecimento de fatores internos e externos, corrigindo ou eliminando as falhas detectadas.

O desempenho sustentável, principalmente a longo prazo, a ser implementado pelo Estado, deve ter características de dinamismo e flexibilidade, oriundos da burocracia neoweberiana, ao mesmo tempo em que é integrado e prospectivo, em razão do elevado nível de instabilidade e volatividade que caracteriza os diversos aspectos, alcançando maior excelência e competitividade.

O planejamento estratégico governamental surge assim como a base da governança participativa fruto e elemento de sustentação da governabilidade, aqui entendida no bojo da relação e interação entre o Estado e a sociedade, oportunizando ações conjuntas que conduzirão a uma sociedade mais justa e digna.

\section{CONSIDERAÇÕES FINAIS}

A sustentabilidade visa, em primeiro plano, um empreendimento que não seja caro e que tenha condições de gerar rápidos frutos, fazendo-se necessário medidas estatais ou políticas que sejam favoráveis a implantação de uma governança participava com a interação entre o Estado e a sociedade.

Nesse diapasão, o planejamento estratégico governamental deve revestir-se de governança participava onde é, simultaneamente, fruto e elemento de sustentação da governabilidade. É a bússola a orientar as economias que o adotam, no sentido destas virem a enfrentar contextualizações envolventes cada vez mais complexas, instáveis e voláteis, de modo a lhes assegurar o estofo necessário para alcançarem, com sucesso, a sustentabilidade econômica sustentável.

Com uma governança participativa há condições de se adentrar o âmbito socioeconômico com a finalidade de alterar alguns fatores da realidade em que os atores vivem e desta forma, tornar o futuro mais próspero, alcançando as gerações futuras, combatendo e erradicando a pobreza e a falta de oportunidade.

De posse de uma economia sustentável criam-se oportunidades também de melhorar todos os outros setores sociais e ambientais, posto que a sociedade em questão torna-se mais livre da dependência de recursos e aquisições de outras nações ou de outros blocos econômicos, 
que ainda não são legítimos entusiastas da participação ativa para a redução da pobreza e não estendem a necessária assistência ao desenvolvimento que o mundo rico deveria fornecer ao mundo pobre, eliminando a exclusão social e a pobreza.

Conclui-se, assim, que a busca pela efetivação do direito ao desenvolvimento deve ser uma ação integrada, trilhando os caminhos da participação entre Estado e sociedade, que de mãos dadas, devem aumentar esforços na luta para a libertação do encarceramento da pobreza atingindo o alvo do crescimento autossustentável.

\section{REFERÊNCIAS}

ARENDT, Hannah .A condição humana. $2^{\mathrm{a}}$ ed. Trad. Roberto Raposo. Rio de Janeiro: Forense Universitária, 1983.

BELLEN, H. M. van. Indicadores de sustentabilidade: uma análise comparativa. 2. ed. Rio de Janeiro: Fundação Getúlio Vargas, 2006.

CECHIN, A.; VEIGA, J. E. da. O fundamento central da economia ecológica. In: MAY, P. H. Economia do meio ambiente: teoria e prática. 2. ed. Rio de Janeiro: Elsevier, 2010

\section{COMISIÓN MUNDIAL DEL MEDIO AMBIENTE Y DEL DESARROLLO (CMMAD). Nuestro Futuro Común. Madrid: Alianza, 1998.}

COSTA, Fernando José Pereira da ; RODRIGUES, Manoel Gonçalves . Governança, Meio Ambiente e Transição de Paradigmas. Janeiro/2016. Disponível em https://www.researchgate.net/publication/289671378_Governanca_Meio_Ambiente_e_Transi cao_de_Paradigmas. Acesso em 27 de abr. de 2017.

DUPAS, Gilberto. Economia Global e Exclusão Social: Pobreza, Emprego, Estado e o Futuro do Capitalismo. $3^{\text {a }}$ ed. São Paulo: Paz e Terra, 2005.

FAUCHEUX, S.; NOËL, J. F. Economia dos recursos naturais e do meio ambiente. Lisboa: Instituto Piaget, 1995.

FEITOSA, Maria Luiza A. M; FRANCO, Fernanda; PETERKE, Sven; VENTURA, Victor A. M. F. Direitos humanos de solidariedade. Curitiba: Appris, 2013.

FEITOSA, Maria Luiza A. M. Exclusão social e pobreza nas interfaces entre o direito econômico do desenvolvimento e o direito humano ao desenvolvimento. In: Direito e Desenvolvimento no Brasil do Século XXI. Brasília: ipea, 2013.

FERRAREZI, Elisabete. Estado e Setor Público não Estatal: Perspectivas para a Gestão de Novas Políticas Sociais. II Congresso Interamericano del CLAD sobre la Reforma del Estado

Rev. de Direito, Economia e Desenvolvimento Sustentável| e-ISSN: 2526-0057| Maranhão | v. 3 | n. 2 | p. 119 - 135 | Jul/Dez. 
y de la Administración Pública, Venezuela, 15-18 de outubro de 1997. Disponível em http://docplayer.com.br/3746348-Estado-e-setor-publico-nao-estatal-perspectivas-para-a-gesta o-de-novas-politicas-sociais. html. Acesso em 15 de abr de 2017.

FONSECA, João Bosco Leopoldino. Direito Econômico. São Paulo: Forense, 2012.

FURTADO, Celso. Em busca de novo modelo: reflexões sobre a crise contemporânea. $2^{\mathrm{a}}$ ed. São Paulo: Paz e Terra, 2002.

KANT, Immanuel. Sobre la paz perpetua. 7 ed. Trad. JoaquínAbellán. Madrid: Tecnos, 2005.

MAY, P. H.; LUSTOSA, M. C.; VINHA, V. (Org.) Economia do meio ambiente: teoria e prática. 2. ed. Rio de Janeiro, Elsevier, 2010,

MAY, P. H. O setor financeiro privado internacional e o meio ambiente: o caso do Brasil. In: CAVALCANTI, C. (Org.). Meio ambiente, desenvolvimento sustentável e políticas públicas. 3. ed. São Paulo: Cortez, 2001.

MESTRINER, Maria Luiza. O Estado entre a filantropia e a Assistência Social. São Paulo: Cortez, 2001, p. 79. FONSECA, João Bosco Leopoldino. Direito Econômico. São Paulo: Forense, 2012.

NOSSO futuro comum. Rio de Janeiro: Fundação Getúlio Vargas, 1988.

PASOLD, Cesar Luiz. Metodologia da Pesquisa Jurídica: Teoria e Prática. 12 ed. São Paulo: Conceito Editorial, 2011.

PORTO, C. Uma introdução ao planejamento estratégico. Boletim Técnico do SENAC, v. 19, n. 2, pp. 22 - 33. Maio - Agosto,1998. Rio de Janeiro.

ROCHA, Joaquim Freitas. Sustentabilidade e finanças públic as responsáveis. Urgência de um direito financeiro equigeracional. p.619-639. In: CORREIA, Fernando Alves, LOUREIRO, João Carlos Loureiro e MACHADO, Jonatas E. M. (orgs). Estudos em homenagem ao prof. Doutor José Joaquim Gomes Canotilho. Coimbra: Coimbra Editora, 2012.

ROMEIRO, A. R. Economia ou economia política da sustentabilidade. In: MAY, P. H. Economia do meio ambiente: teoria e prática. 2. ed. Rio de Janeiro: Elsevier, 2010. p. 1-32.

SACHS, Jeffrey D. O fim da pobreza: como acabar com a miséria mundial nos próximos vinte anos. São Paulo: Companhia das letra, 2005.

SACHS, I. Caminhos para o desenvolvimento sustentável. Rio de Janeiro: Garamond, 2000

SACHS, I. Caminhos para o desenvolvimento sustentável. Rio de Janeiro: Garamond, 2009.

SEN, Amartya; KLIKSBERG, Bernardo. As pessoas em primeiro lugar: a ética do desenvolvimento e os problemas do mundo globalizado. São Paulo: Companhia das Letras, 2010 .

Rev. de Direito, Economia e Desenvolvimento Sustentável| e-ISSN: 2526-0057| Maranhão | v. 3 | n. 2 | p. 119 - 135 | Jul/Dez. 
SORTO, Fredys Orlando; MAIA, Mário Sérgio Falcão. Cidadania, direitos sociais e indivisibilidade dos direitos humanos. In: LEAL, Mônica Clarissa Henning (org.) Trabalho, constituição e cidadania: reflexões acerca do papel do constitucionalismo na ordem democrática. Porto Alegre: Verbo Jurídico, 2009. 